\title{
KONSEP MAKANAN HALAL DAN THOYYIB DALAM TRADISI MASYARAKAT MELAYU RIAU
}

\author{
Edison $^{1 *}$, Rini Lestari ${ }^{2}$ \\ ${ }^{1}$ Universitas Abdurrab Pekanbaru, INDONESIA \\ ${ }^{2}$ Universitas Abdurrab Pekanbaru, INDONESIA \\ *Correspondence: edison@univrab.ac.id
}

\begin{abstract}
Besides receiving education and teaching about the virtues of halal food according to the Melayu tradition, the Riau community should also get an understanding of the virtues of halal food based on the Islamic law. This study aims to analyze the concept of the Riau Malay community in maintaining halal food, and what is the manners eat traditions of Melayu society closely related to eating etiquette in Islam. This research was a field study that collects data based on interviews, observation and documentation. The results showed that the food of the Melayu community has met the elements of halal and tayyib as stipulated in culinary fiqh in Islamic law. The motive of the Melayu community to eat with halal and thoyyib criteria's food is more due to habits and traditions that have been taught from generation to generation through the advice and teachings of the elders. This study also revealed that the type of food that is legalized is more than the type of food that is forbidden. Although the Malay community has been taught about the concept of halal food and thoyyib, but the teaching did not contain systematic content and had not yet reached a comprehensive level of understanding.
\end{abstract}

\begin{abstract}
Abstrak
Masyarakat Riau selain mendapat pendidikan dan pengajaran tentang keutamaan makanan halal menurut tradisi Melayu, seharusnya juga mendapat pemahaman tentang keutamaan makanan halal berdasarkan ketentuan syariat Islam. Penelitian ini bertujuan menganalisis konsep masyarakat Melayu Riau dalam menjaga kehalalan makanan, jenis makanan apa saja yang menunjukkan bahwa masyarakat Melayu hanya memakan makanan yang halal dan thoyyib, dan adab makan apa saja yang menjadi tradisi masyarakat Melayu nan erat kaitannya dengan adab makan dalam Islam. Penelitian ini adalah studi lapangan yang mengumpulkan data berdasarkan wawancara, observasi dan dokumentasi. Hasil penelitian menunjukkan bahwa Makanan masyarakat Melayu sudah memenuhi unsur halal dan thoyyib sebagaimana ketentuan fiqih kuliner dalam syariat Islam. Motif masyarakat Melayu hanya memakan makanan dengan kriteria halal dan thoyyib lebih dikarenakan karena kebiasaan dan tradisi yang diajarkan turun temurun melalui pendekatan petuah dan ajaran para tetua. Penelitian ini juga mengungkap bahwa jenis makanan yang dihalalkan itu lebih banyak dari pada makanan yang diharamkan. Meskipun masyarakat Melayu sudah pernah mendapat pengajaran tentang konsep makanan halal dan thoyyib, namun pengajaran tersebut belum memuat isi yang sistematis dan belum sampai pada tingkat pemahaman yang menyeluruh.
\end{abstract}

\section{Article History}

Received: 21-10-2020,

Revised: $30-12-2020$,

Accepted: $31-12-2020$

Keywords:

Halal and Thoyyib Food;

Melayu Community;

Tradition;

\section{Histori Artikel}

Diterima: 21-10-2020

Direvisi: $30-12-2020$

Disetujui: 31-12-2020

Kata Kunci:

Makanan Halal dan

Thoyyib;

Masyarakat Melayu;

Tradisi

\section{(C) 2020 Edison, Rini Lestari}

This work is licensed under a Creative Commons Attribution-ShareAlike 4.0 International License.

\section{A. Pendahuluan}

Masyarakat Melayu menjadi salah satu komponen penting umat Islam di nusantara yang tentunya menarik untuk dikaji setiap tata kehidupannya mulai dari adat budaya, implementasi hukum Islam, sistem pembagian waris, nilai-nilai seni dan olahraga, adat berpakaian dan berhias, 
konsep pernikahan sampai kepada kaidah bermuamalat dalam bentang kehidupan masyarakat Muslim Melayu itu sendiri.

Masyarakat Melayu yang sangat berafiliasi dengan Islam dan sangat mengagungkan ketuhanan Allah SWT sudah barang tentu sangat memelihara makanannya hanya pada yang halal dan thoyyib. Peradaban Muslim Melayu di masa lalu pastinya sangat memperhatikan apa yang mereka makan dan bagaimana cara memperolehnya agar selalu sesuai dengan tuntunan Islam. Namun, masyarakat Melayu yang hidup di masa sekarang ini menghadapi tantangan masuknya peradaban luar yang juga membuka masuknya jenis makanan yang belum dikenal sebelumnya. Oleh karena itu dibutuhkan kesesuaian pemahaman antara konsep makanan halal dan thoyyib dalam Islam yang syariatnya mengatur kehidupan manusia sepanjang zaman, dengan konsep makanan halal dan thoyyib masyarakat Melayu.

Kajian mengenai internalisasi nilai-nilai Islam terhadap perilaku sosial orang Melayu menemukan bahwa dalam kehidupan sehari-hari masyarakat Melayu Riau sepertinya telah mulai keluar dari koridor Islam, karena arus dan gelombang dari luar diterima dengan permissive tanpa menggunakan filter, sehingga salah satu fenomenanya orang Melayu mulai berani coba-coba mencicipi semua makanan yang berasal dari luar tanpa mempertimbangkan halal dan thoyyib-nya. ${ }^{1}$

Pemahaman umat Islam terhadap pentingnya menghindari makanan yang diharamkan dan hanya mengkonsumsi makanan halal dan thoyyib harusnya meningkatkan tren kepedulian terhadap makanan halal. Kepercayaan dan pemahaman agama menjadi pemantik utama terhadap kesadaran muslim tentang konsumsi makanan halal. ${ }^{2}$

Beberapa produsen makanan yang tadinya tidak begitu memperhatikan secara ketat kehalalan produksi makanan dan minuman mereka dengan pertimbangan bisnis kemudian justru beralih menyesuaikan produk makanan dan minuman mereka agar sesuai dengan standar halal. Sebagaimana kajian yang berjudul A Case Study On A Food Caterer : The Halal Food Ecosystem yang membahas seputar perusahaan makanan dan minuman yang ingin mengembangkan bisnisnya menjadi makanan halal kemudian menemukan bahwa makanan yang terjamin kehalalannya disadari sebagai makanan yang higienis dan berkualitas baik ${ }^{3}$.

Sebuah kajian yang mempelajari tentang Halal Integrity In The Food Supply Chain menemukan bahwa selama ini ada perhatian yang luput pada industri makanan di dunia internasional terhadap kehalalan produk mereka. Kajian ini juga menambahkan bahwa konsep sadar halal merupakan faktor yang sangat penting untuk diperhatikan dalam pengembangan produk makanan ${ }^{4}$. Semua kajian menunjukkan bahwa baik masyarakat modern maupun masyarakat tradisional sangat menyadari pentingnya kehalalan makanan untuk keberlangsungan hidup dan ekosistem mereka.

Tiara Khoerunnisa, Sunaryo, Astrid Puspa ningrum melakukan kajian terhadap pengaruh kepercayaan agama terhadap keputusan pembelian makanan halal namun hanya terbatas pada lingkup penduduk Kota Malang. Artikel ini membahas tentang pengaruh kepercayaan agama, logo halal, pemaparan, dan alasan kesehatan terhadap kesadaran merek dan keputusan pembelian

\footnotetext{
${ }^{1}$ Ellya Roza, "Internalisasi Nilai Islam Dan Tamadun Melayu Terhadap Perilaku Sosial Orang Melayu Riau," TOLERANSI: Media Ilmiah Komunikasi Umat Beragama 6, no. 1 (2014): 16-35, https://doi.org/10.24014/trs.v6i1.894.

2 Abdul Raufu Ambali and Ahmad Naqiyuddin Bakar, "People's Awareness on Halal Foods and Products: Potential Issues for Policy-Makers," Procedia - Social and Behavioral Sciences 121, no. September 2012 (2014): 3-25, https://doi.org/10.1016/j.sbspro.2014.01.1104.

${ }^{3}$ Azyyati Mat Zam, Zulkifflee Mohamed, and Mohd Yaziz Mohd Isa, "A Case Study on Food Caterer : The Halal Food Eco-System .," JAABR, no. May (2014).

4 Jan Mei Soon, Mahmood Chandia, and Joe Mac Regenstein, "Halal Integrity in the Food Supply Chain," British Food Journal 119, no. 1 (2017): 39-51, https://doi.org/10.1108/BFJ-04-2016-0150.
} 
makanan halal. Hasil artikel menunjukkan bahwa terdapat pengaruh yang signifikan secara langsung antara kepercayaan agama terhadap keputusan pembelian, kepercayaan agama terhadap keputusan pembelian makanan halal. ${ }^{5}$

Selama beberapa dekade terakhir lini masa negara-negara di Asia Tenggara yang berbasis Melayu memenuhi perbincangan mereka di wilayah ilmiah dan non ilmiah tentang urgensi makanan halal dan thoyyib. Beberapa kajian mengenai tradisi dan makanan halal juga banyak bermunculan. Talisa Rahma dan Indah Fatmawati mengkaji tentang pengaruh keyakinan religius terhadap kesadaran masyarakat pada produk makanan halal yang juga menyoroti bahwa faktor keyakinan dan budaya turut mempengaruhi perilaku konsumen dalam mengkonsumsi makanan halal dan thoyyib. ${ }^{6}$

Konsep seputar makanan halal dan thoyyib di kalangan masyarakat Melayu menjadi dibutuhkan dalam rangka memperkuat ketersambungan amal masyarakat Melayu dengan Islam. Konsep pemahaman makanan halal dan thoyyib yang lebih terstruktur dalam rangka menjaga umat Muslim dari masuknya makanan haram kedalam tubuh menjadi sangat diperlukan. Terlebih di era milenial sekarang ini begitu ramai dan berkembang pesatnya usaha-usaha kuliner atau restoran bernuansa asing yang menyajikan beraneka ragam hidangan sesuai dengan karakteristik makanan negara asalnya, di mana di Negara asalnya produk-produk tersebut juga identik menyajikan hidangan non-halal. Kajian tentang tradisi pola makan masyarakat Melayu menjadi fokus pembeda dari artikel lainnya.

Berdasarkan latar belakang tersebut, maka artikel ini menganalisis konsep masyarakat Melayu Riau dalam menjaga kehalalan makanan, jenis makanan apa saja yang menunjukkan bahwa masyarakat Melayu hanya memakan makanan yang halal dan thoyyib, dan bagaimanakah adab makan yang menjadi tradisi masyarakat Melayu yang erat kaitannya dengan adab makan dalam Islam.

\section{B. Metode Penelitian}

Artikel ini menggunakan pendekatan kualitatif merupakan studi lapangan tentang tradisi pola makan masyarakat Melayu Riau. Artikel ini juga bersifat etnografis yakni artikel tentang etnis kebudayaan. Subjek artikel ini adalah tradisi pola masyarakat Melayu Riau. Tahapan pengumpulan data dilakukan melalui tiga kegiatan, yakni wawancara, observasi, dokumentasi dan catatan lapangan. Analisis data mengacu pada metode Miles dan Huberman yang meliputi empat kegiatan, yaitu pengumpulan data, reduksi data, penyajian data dan penyimpulan dan pembahasan data berdasarkan sumber literatur yang relevan. Keseluruhan kegiatan tersebut adalah proses siklus interaktif ${ }^{7}$.

\section{Pembahasan atau Analisis}

Jenis makanan yang biasa dimakan di kalangan masyarakat Melayu adalah makanan pokok seperti nasi, ubi, jagung dan sagu dengan aneka olahannya yang dilengkapi lauk pauk berupa ikan laut, ikan sungai, dan hasil laut lainnya seperti udang dan kerang. Masyarakat Melayu juga berkreasi dengan membuat jajanan pasar berbahan tepung yang diolah menjadi aneka kuih muih

5 Tiara Khoerunnisa, Sunaryo, and Astrid Puspaningrum, "Pengaruh Kepercayaan Agama, Logo Halal, Pemaparan, Dan Alasan Kesehatan Terhadap Kesadaran Merek Dan Keputusan Pembelian Makanan Halal Pada Penduduk Kota Malang,” Ekonomi Bisnis 21, no. 1 (2016): 36-45.

${ }^{6}$ T. Pramintasari and I. Fatmawati, "Pengaruh Keyakinan Religius, Peran Sertifikasi Halal, Paparan Informasi, Dan Alasan Kesehatan Terhadap Kesadaran Masyarakat Pada Produk Makanan Halal," Jurnal Manajemen Bisnis 8, no. 1 (2017): 1-33.

${ }^{7}$ Albi Anggito and Johan Setiawan, "Metode Penelitian Kualitatif” (Jakarta: CV Jejak, 2018). 
seperti bolu kemojo dan kue bangkit. Hal ini sesuai dengan apa yang disampaikan oleh Sayyid Sabiq bahwa makanan atau dalam Islam disebut Ath 'imah adalah segala sesuatu yang dimakan dan dikonsumsi oleh manusia, baik makanan pokok maupun jenis makanan lainnya. ${ }^{8}$

Semua hasil laut dan sungai seperti ikan, udang, dan kerang boleh dimakan, sedangkan ikan beracun dan ikan duri-duri tidak boleh dimakan. Menurut tradisi masyarakat Melayu, khususnya Melayu Indragiri, ikan duri-duri dilarang untuk dimakan karena ada persumpahan orang tua-tua dulu, di samping juga dipercaya mendatangkan penyakit. Makanan beracun, apapun jenisnya memang diharamkan dalam Islam karena bersifat merusak tubuh hingga menyebabkan kematian ${ }^{9}$ Makanan beracun atau racun itu sendiri ada yang diproduksi di pabrik, maupun racun yang berasal dari alam, termasuk makanan yang diharamkan dalam hal ini adalah ikan yang mengandung racun. Sehingga dengan demikian illat keharaman ikan beracun, bukan karena jenis ikannya, melainkan karena racun yang terdapat pada ikan tersebut.

Ikan dan hewan yang hidup di air halal dimakan, yakni dengan alasan ikan termasuk bangkai yang halal. Hal ini memang sesuai dengan prinsip bangkai yang dihalalkan. Meskipun secara umum, bangkai itu haram dimakan, namun di dalam Islam ada bangkai yang dikecualikan boleh dimakan, yakni bangkai ikan, dan bangkai belalang.

Sabda Rasulullah SAW tentang halalnya dua bangkai,

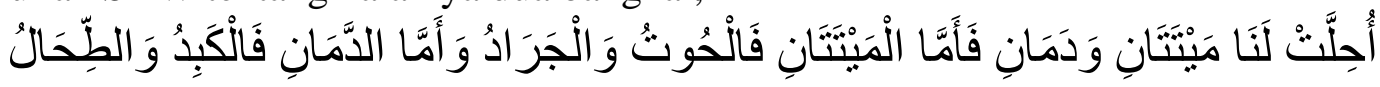

Telah dihalalkan bagi kami dua bangkai dan dua darah. Dua bangkai itu adalah ikan dan belalang. Dua darah itu adalah hati dan limpa (HR. Ahmad dan Al Baihaqi).

Beberapa jenis makanan masyarakat Melayu disajikan pada Gambar berikut :
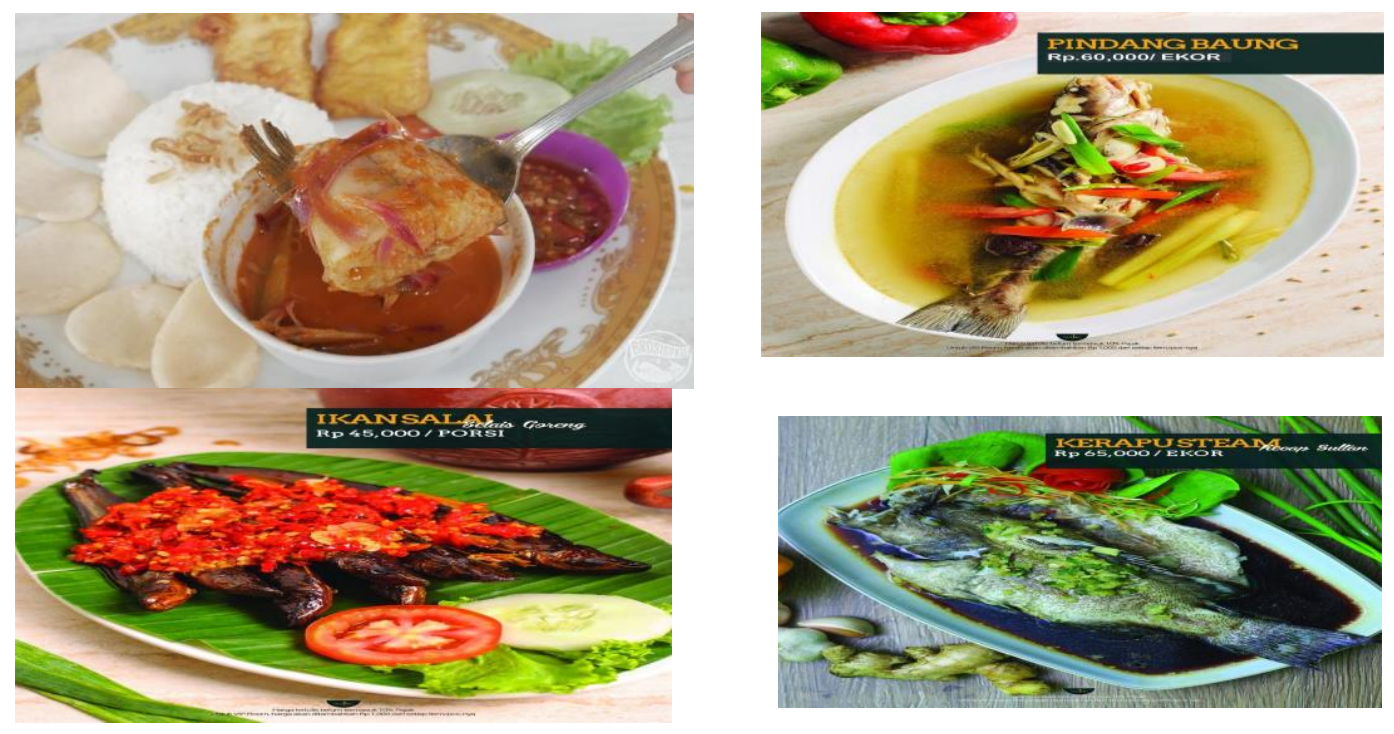

Gambar 1. Salah satu jenis makanan masyarakat Melayu

Dari pemaparan diatas ditemukan bahwa makanan darat yang dihalalkan itu banyak jenisnya. Makanan darat yang dilarang seperti ular, anjing dan babi. Adapun jenis tumbuhan yang dilarang adalah tumbuhan yang tidak lazim dimakan. Hewan-hewan tersebut diharamkan karena mendatangkan bahaya bagi tubuh dan sudah menjadi pantang larang secara turun-temurun. Maka,

\footnotetext{
${ }^{8}$ Sayyid Sabiq, "Fiqhu Sunnah" (Depok: Fathan Media Prima, 2015).

${ }^{9}$ Ahmad Sarwat, "Seri Fiqih Kehidupan (9) Kuliner" (Jakarta: Rumah Fiqih Publishing, 2017).
} 
dalam hal ini perlu diluruskan bahwa alasan pengharaman makanan yang disebutkan di atas tidak semata karena mendatangkan bahaya dan pantang larang, namun diharamkannya anjing, babi, adalah karena kenajisannya. Sedangkan ular haram dimakan karena tergolong hewan yang diperintahkan untuk membunuhnya dalam Islam.

Hal ini berdasarkan hadits Nabi Muhammad SAW yang diriwayatkan oleh Aisyah RA,

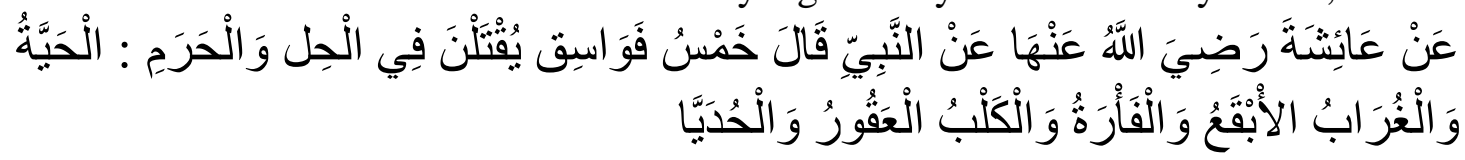

Dari Aisyah RA Lima binatang jahat yang boleh dibunuh: ular, burung gagak, tikus, anjing hitam dan burung buas (HR. Muslim).

Makanan yang ditetapkan kehalalannya oleh syariat adalah hewan laut dan semua jenis makanan yang dikeluarkan oleh laut. Hewan laut tidak perlu disembelih sebagaimana firman Allah SWT

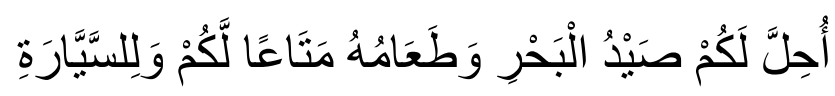

Dihalalkan bagimu binatang buruan laut dan makanan (yang berasal) dari laut sebagai makanan yang lezat bagimu, dan bagi orang-orang yang dalam perjalanan ... (Al Maidah : 96)

Termasuk pula dihalalkan dalam hal ini adalah ikan yang diawetkan baik dalam kemasan sarden, ikan asin maupun ikan salai agar dapat bertahan lama dan tidak lekas rusak. Semua olahan ikan yang diawetkan tersebut halal dimakan selama tidak mengandung bahaya. Namun, apabila mengandung bahaya, maka ikan yang diawetkan tersebut menjadi terlarang karena masuk dalam kriteria makanan madharat (yang membahayakan). Sedangkan hewan darat yang ditetapkan kehalalannya adalah hewan ternak yakni unta, sapi, kerbau, kambing, domba dan ditambahkan pula kedalamnya yakni kijang. Di dalam As Sunnah terdapat pembolehan memakan ayam, kuda, keledai liar dan kelinci. ${ }^{10}$

Allah SWT berfirman :

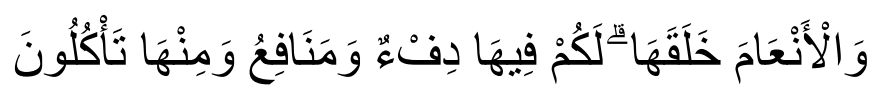

Dan Dia telah menciptakan binatang ternak untuk kamu; padanya ada (bulu) yang menghangatkan dan berbagai-bagai manfaat, dan sebahagiannya kamu makan.(An Nahl : 5)

Allah SWT juga berfirman dalam ayat lainnya yakni surat Al Maaidah ayat1 :

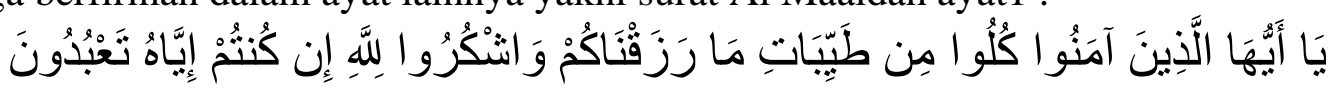

Hai orang-orang yang beriman, penuhilah aqad-aqad itu. Dihalalkan bagimu binatang ternak, kecuali yang akan disebutkan kepadamu.

Ada beberapa petuah adab makan dan minum yang selalu dilakukan yakni memulakan aktivitas makan dengan membaca Basmalah, makan bersama-sama, makan jangan mubazir, dan duduk dengan tawadhu ketika makan. Tasmiyah atau menyebut nama Allah adalah membaca lafadz Basmallah memang sangat dianjurkan dalam memulakan setiap aktivitas yang baik, terkhusus untuk aktivitas makan, Nabi SAW bersabda, dari Aisyah RA :

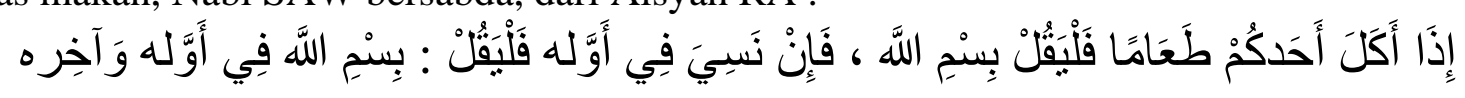

Apabila kalian menyantap makanan, ucapkanlah : Bismillah. Jika kalian lupa di awalnya, maka selesai makan, ucapkanlah :Bismillahi fi awwalihi wa akhirihi. (HR. At Tirmidzi).

${ }^{10}$ Sabiq, "Fiqhu Sunnah." 
Imam Al Ghazali dalam kitabnya Adab Fiddin juga menyampaikan bahwa sebelum minum hendaklah melihat kearah gelas, kemudian mengucap Bismillah dan mengucapkan Alhamdulillah setelah minum. Imam Al Ghazali menambahkan, minumlah seteguk demi seteguk. Jangan mengumpulkan air di dalam mulut terlebih dahulu untuk kemudian diminum sekaligus, melainkan minumlah dengan beberapa kali tegukan disertai beberapa tarikan napas dan diiringi ucapan Hamdalah. Tuntunan Islam memang sangat menganjurkan makan bersama-sama atau makan berjama'ah demi mendapatkan keberkahan dari makanan.

Dalam tradisi masyarakat Melayu, dilarang makan berserak atau mubazir. Berkenaan dengan praktik mubazir terhadap makanan yaitu sikap membuang-buang makanan atau sikap tabzir, maka Al Qur'an sendiri langsung melarang dengan tegas sikap tabzir ini secara umum.

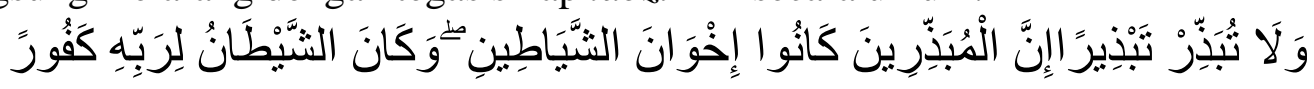

... Dan janganlah kamu menghambur-hamburkan (hartamu) secara boros. Sesungguhnya pemboros-pemboros itu adalah saudara-saudara setan dan setan itu adalah sangat ingkar kepada Tuhannya. (Al Israa : 26-27).

Pemahaman masyarakat Melayu tentang definisi makanan halal mengemukakan bahwa makanan halal itu adalah makanan yang baik, berbuah manfaat dan tidak mendatangkan bahaya, makanan juga disebut halal, jika diperoleh dengan cara-cara yang halal. Pemahaman tersebut sesuai dengan apa yang disampaikan oleh Yusuf Qardhawi dalam kitabnya Halal dan Haram dalam Islam yang menyebutkan bahwa Islam menghalalkan segala yang baik. Tatkala kelompok manusia di luar pemahaman Islam masih rancu dalam memahami apa-apa saja yang boleh dimakan dan apa yang dilarang, maka Islam tampil dalam posisi di tengah, tidak berlebihan tentang kebebasan makanan dan tidak condong pula pada paham ekstrimis dalam soal larangan. ${ }^{11}$

Pemahaman masyarakat Melayu tentang definisi makanan thoyyib juga sangat tepat, yakni makanan yang baik, sehat, makanan bergizi dan tidak merusak tubuh. Buya Hamka menjelaskan bahwa makanan thoyyib yang dimaksud dalam surat Al Baqarah ayat 172 adalah makanan yang syarat akan gizi, dan higienis sesuai dengan standar kesehatan. Makanan thoyyib itu juga diperoleh dengan cara-cara yang baik. Dengan demikian, belum tentu semua yang halal itu baik. Makanan halal jika diperoleh dari hasil mencuri, maka tidak baik. Dari segi kesehatan, makanan yang berkolesterol tinggi bisa jadi halal, namun tidak baik bagi kesehatan, terkhusus bagi penderita darah tinggi. Dalam konteks yang lebih luas, konsep makanan thoyyib menasehatkan kepada umat Islam agar jangan makan di sembarang tempat. Hindari makan di suasana lokasi tempat makan yang jorok dan kotor. Meskipun makanannya halal, namun potensi paparan penyakit juga tentunya sangat rentan. $^{12}$

Beberapa upaya agar makanan terjaga kehalalan dan thoyyyib-nya yaitu dengan memperhatikan cara memperoleh makanan, membiasakan memakan sembelihan hewan yang diternak sendiri atau tanaman di sekitar kampung yang dikenali asal usulnya. Semua upaya tersebut juga terkait dengan tindakan mencari tahu hukum makanan sebelum makan. Hal ini penting, agar jangan sampai seorang Muslim memakan makanan yang tidak halal dan baru diketahui belakangan setelah makanan itu masuk kedalam perut. ${ }^{13}$

Makanan impor seperti daging yang diimpor dari luar negeri yakni negeri yang bukan Islam pada dasarnya halal dimakan dengan dua syarat. Pertama, daging tersebut termasuk daging yang memenuhi kriteria halal. Kedua, Daging tersebut disembelih secara syar'i. Apabila kedua syarat

\footnotetext{
${ }^{11}$ Yusuf Qaradhawy and Mohd Hafiz, Halal Dan Haram Dalam Islam (Selangor: PTS Publishing House, 2016).

${ }^{12}$ Prof Hamka, Tafsir Al Azhar Jilid 1 (Jakarta: Gema Insani, 2015).

${ }^{13}$ Sarwat, "Seri Fiqih Kehidupan (9) Kuliner."
} 
tersebut tidak terpenuhi, misalnya daging tersebut adalah termasuk daging yang diharamkan, seperti daging babi yang disamarkan, atau daging tersebut disembelih dengan cara yang tidak syar'i, maka memakan daging tersebut menjadi terlarang. ${ }^{14}$

Pengajaran tentang konsep makanan halal dan thoyyib sebenarnya cukup disajikan dengan memaparkan kriteria makanan haram dan buruk. Karena pada dasarnya dalam Islam, makanan yang dihalalkan lebih banyak dari pada yang makanan dilarang. Dengan mengenali kriteria makanan yang haram, maka setiap Muslim akan mudah mengenal mana makanan yang halal. Pada intinya, semua makanan itu halal, selama tidak ada satupun keterangan yang menyebutkan keharamannya.

Dalam fiqih kuliner, kriteria umum keharaman makanan itu ada tiga, yakni makanan najis atau mengandung najis; makanan atau minuman yang memabukkan yakni benda muskir yang mendatangkan efek mabuk baik dengan cara diminum, dihisap, disuntikkan atau dilinting; serta makanan madharat.

Kriteria khusus makanan hewani yang diharamkan meliputi hewan yang diharamkan langsung di dalam Al Qur'an dan hadits, hewan najis, bangkai baik hewan yang tidak disembelih secara syar'I maupun bagian potongan tubuh hewan yang masih hidup. Diharamkan pula oleh syariat Islam hewan yang hidup di dua alam, hewan buas, hewan yang diperintahkan untuk dibunuh dan hewan yang dilarang untuk dibunuh. ${ }^{15}$

Dalam pemahaman masyarakat Melayu tentang label halal pada produk makanan dan hubungannya dengan kehalalan makanan sebagai syarat mutlak kehalalan makanan, maka perlu diluruskan bahwa makanan halal itu jumlah dan jenisnya sangat banyak. Makanan yang tidak ada label halalnya belum tentu haram. Fungsi label halal sesungguhnya, selain membantu dan memudahkan masyarakat agar lebih berhati-hati mengkonsumsi produk makanan dan minuman juga sebagai bentukpembelaan dan penjagaan terhadap umat Islam agar terhindar dari produk yang tidak halal ${ }^{16}$.

Makanan haram yang diketahui oleh masyarakat Melayu dan telah menjadi tuntunan tanpa naskah secara turun temurun pada dasarnya tidak jauh berbeda dengan apa yang dilarang dalam syariat Islam. Adapun makanan haram dalam Islam adalah kuliner yang berasal dari hewan seperti anjing, babi, biawak dan kadal semuanya haram dimakan, demikian pula hewan berkuku tajam dan bertaring. Masyarakat Melayu juga mengharamkan bangkai dan najis, khamr, serta makanan dan minuman yang memabukkan, dan semua yang mengandung racun.

Kriteria pertama dari makanan yang haram adalah bila makanan itu merupakan benda yang hukumnya najis. Termasuk pula di dalamnya jika makanan itu suci, namun terkontaminasi dengan benda najis. Kaidah penting terkait najis adalah bahwa semua benda najis itu haram untuk dimakan. Hewan najis yang haram dimakan di antaranya adalah babi, anjing dan hewan buas. Ketiga hewan tersebut hukumnya haram dimakan baik dalam kondisi hewan itu masih hidup maupun dalam kondisi sudah menjadi bangkai. Para ulama sepakat mengatakan bahwa babi itu najis pada keseluruhan tubuhnya, termasuk juga bulu, keringat, dan ludahnya.

Makanan halal yang bercampur dengan benda najis, agar tetap bias dimakan, maka benda najis itu harus dipisahkan dari makanan halal tersebut. Jika makanan atau minuman itu berwujud cair, maka semuanya menjadi najis karena sudah bercampur baur dengan sesuatu yang najis ${ }^{17}$. Makanan najis atau mengandung najis adalah produk makanan berbahan dasar darah, seperti sup

\footnotetext{
${ }^{14}$ Sabiq, "Fiqhu Sunnah."

15 Sarwat, "Seri Fiqih Kehidupan (9) Kuliner."

${ }^{16}$ Luky Nugroho, Tidak Ada Label Halal MUI : Haram? (Jakarta: Rumah Fiqih Publishing, 2018).

${ }^{17}$ Sabiq, "Fiqhu Sunnah."
} 
darah, sosis darah, marus (darah hewan yang dibekukan), lawar (urap dengan saos darah), dan kue darah. ${ }^{18}$

Termasuk kategori makanan yang diharamkan karena kenajisannya adalah bangkai yakni hewan yang tidak disembelih sesuai syariat seperti hewan yang mati tercekik, dipukul, yang jatuh, terlindas atau diterkam binatang buas lainnya. Allah SWT berfirman:

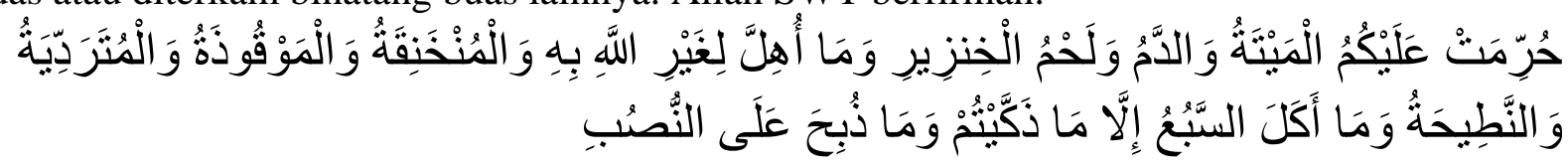

Diharamkan bagimu (memakan) bangkai, darah, daging babi, (daging hewan) yang disembelih atas nama selain Allah, yang tercekik, yang terpukul, yang jatuh, yang ditanduk, dan diterkam binatang buas, kecuali yang sempat kamu menyembelihnya, dan (diharamkan bagimu) yang disembelih untuk berhala... (Al Maaidah : 3)

Kriteria makanan haram berikutnya adalah khamr. Mengenai khamr yang dimaksud dalam hal ini adalah muskir yakni segala makanan dan minuman yang memabukkan baik dengan cara diminum, dimakan, ditelan, dihisap, dihirup, dan disuntikkan. Prinsipnya, segala jenis makanan, minuman, atau apapun yang dikonsumsi manusia yang mengakibatkan mabuk, maka hukumnya haram. Kriteria ketiga yang seringkali luput dari pemahaman masyarakat Muslim adalah tentang keharaman makanan madharat. Makanan madharat adalah makanan yang buruk keadaanya, faqr dan menyakitkan pada badan. ${ }^{19}$ Masyarakat cenderung kurang menyadari bahwa di sekeliling mereka banyak makanan yang berstatus sebagai makanan madharat. Makanan yang sudah barang tentu bersifat madharat adalah racun baik buatan manusia, buatan pabrik dan racun yang berasal dari alam. Orang yang dengan sengaja mengkonsumsi racun dengan tujuan bunuh diri akan kekal selamanya di neraka.

Makanan yang sudah terkontaminasi racun juga haram dimakan karena akan menimbulkan kemudharatan yang lebihluas. Makanan kadaluwarsa juga tergolong makanan madharat. Orang yang mengkonsumsi makanan yang sudah kadaluwarsa akan merasakan pusing, mual, diare, sesak nafas dan bias mengakibatkan kematian. Mengkonsumsi makanan kadaluwarsa dalam frekuensi sering dan berkelanjutan bisa menyebabkan kanker. Makanan madharat lainnya adalah setiap makanan berbahan pengawet dan pewarna yang melewati ambang batas yang ditoleransi.

Selanjutnya, di antara benda yang banyak disebut-sebut mendatangkan madharat pada saat sekarang ini adalah rokok. Para ulama memang ada yang membolehkan, ada yang menghukuminya makruh dan tidak sedikit pula ulama yang mengharamkan rokok. Keharaman rokok memang tidak disebutkan dalam Al Qur'an, hadits maupun kitab para ulama klasik. Hal ini dikarenakan, rokok yang dikenal pada masa lampau hanyalah tembakau yang dilinting dengan kertas atau daun bambu yang terkadang juga ditambahi racikan bahan alam lainnya seperti cengkeh, sehingga rokok pada masa lampau cenderung tidak membahayakan jika dibandingkan dengan produk rokok masa sekarang.

Masyarakat Melayu mengemukakan bahwa makanan yang thoyyib itu adalah makanan yang menyehatkan, baik menurut Islam, bersih, bergizi dan tidak membahayakan tubuh. Penjelasan tersebut sesuai dengan konsep makanan thoyyib di dalam Islam yang menegaskan bahwa setiap makanan halal belum tentu thoyyib untuk dikonsumsi. Makanan halal pada umumnya adalah makanan yang baik, namun belum tentu semua makanan yang halal itu baik ${ }^{20}$.

\footnotetext{
${ }^{18}$ Sarwat, "Seri Fiqih Kehidupan (9) Kuliner."

${ }^{19}$ Sarwat.

${ }^{20}$ Nugroho, Tidak Ada Label Halal MUI : Haram?
} 
Buah durian, misalnya adalah buah yang sifatnya halal mulai dari bagian daging buah, biji hingga kulitnya. Namun kulit durian itu sendiri tidak thoyyib untuk dimakan karena disentuh saja bias melukai diri, apalagi sampai dimakan. Makanan halal lainnya seperti sate kambing, yang memang halal untuk dikonsumsi namun akan menjadi tidak thoyyib jika seandainya dikonsumsi oleh individu-individu yang memiliki riwayat penyakit berbahaya yang disarankan untuk tidak mengkonsumsinya ${ }^{21}$.

Oleh karena itu, Islam tidak hanya fokus pada status kehalalan makanan saja, tetapi status thoyyib makanan juga menjadi perhatian syariat agama Islam yang dianut oleh masyarakat Melayu. Untuk membuktikan konsep ini tim peneliti mengadakan observasi ke Pondok Asam Pedas Sinar Kampar. Hasil penelusuran yang membuktikan bahwa makanan masyarakat Melayu memang makanan yang thoyyib dapat dibuktikan dengan dominasi ikan sungai atau ikan air tawar sebagai lauk pauk yang notabenenya disajikan sebagai olahan ikan segar yang bersumber langsung dari sungai yang dekat dengan masyarakat Riau maupun pusat penangkaran ikan air tawar yang terdapat di seantero daerah provinsi Riau. Makanan dengan lauk ikan sungai ditampilkan pada gambar berikut :

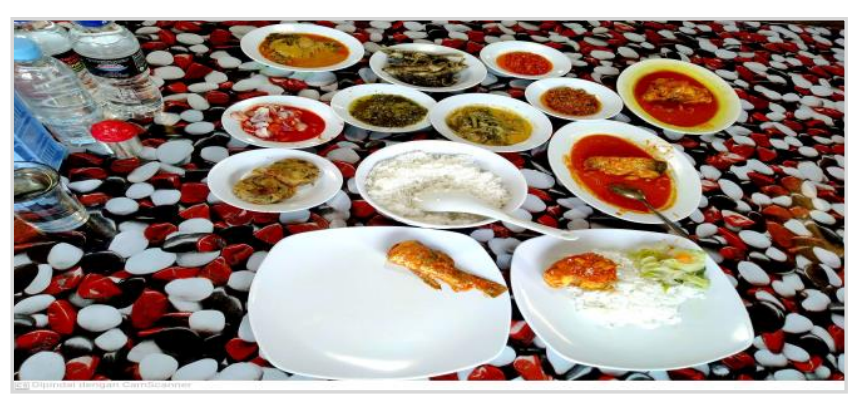

Gambar 2: Makanan Thoyyib Masyarakat Melayu

Olahan ikan segar yang bersumber langsung dari sungai maupun pusat penangkaran ikan air tawar tersebut lebih memenuhi unsur thoyyib daripada ikan laut yang banyak beredar di Riau. Ikan laut yang beredar di kota seperti Pekanbaru dan beberapa kabupaten lainnya cenderung mengandung zat pengawet sebagai upaya memperlambat pembusukan karena membutuhkan waktu yang lama sejak masa penangkapan ikan di laut hingga masa pendistribusian. Akumulasi zat pengawet dalam waktu yang lama jika dikonsumsi oleh tubuh tentunya berefek buruk bagi kesehatan tubuh, meskipun ikan laut yang dimakan tergolong bangkai yang dihalalkan di dalam Islam.

Seorang Muslim juga harus meninggalkan makanan yang tidak thoyyib, meskipun halal akan mengancam kesehatan tubuh, memicu penyakit dan merusak diri sendiri. Siapapun yang dengan sengaja memakan makanan yang tidak thoyyib, pada gilirannya cepat atau lambat akan menurunkan fungsi tubuhnya sehingga tidak dapat menjalankan tugas sebagai hamba dan sebagai khalifah dengan baik.

Kebolehan pemanfaatan makanan haram dengan alasan darurat sangat tergantung dari seberapa darurat keadaan yang sedang dihadapi sehingga harus mengkonsumsi yang haram. Sedangkan kondisi darurat itu sendiri adalah hal-hal genting yang berisiko terancamnya keselamatan jiwa yang bila tidak diambil langkah penanganannya, nyawanya bias melayang saat itu

${ }^{21}$ Tim Navari, 1001 Makanan Sehat (Jakarta: Elex Media Komputindo, 2015). 
juga. Allah SWT mengharamkan berobat dengan yang haram, karena pada dasarnya setiap penyakit pasti ada obat dari bahan yang halal ${ }^{22}$.

Jika tubuh seorang hamba rutin memakan makanan haram, baik secara zat dan atau haram dari cara memperolehnya, maka notabenenya tubuh biologis sang hamba akan terbentuk dari asupan gizi makanan haram, dan keharamannya selalu melekat kepada diri hamba tersebut meskipun dirinya berada di tempat suci. Dengan demikian, bentuk penghambaan dan ibadahnya akan menjadi sia-sia.

Suatu makanan yang halal zatnya bisa menjadi haram jika disembelih dan disajikan untuk berhala dan sesajen. Yusuf Qardhawi menyebutkan bahwa rincian sumber makanan hewani yang diharamkan adalah hewan yang disembelih untuk berhala, di mana prosesi penyembelihannya tepat berada di dekat berhala itu (satu tempat); atau hewan yang disembelih dengan niat atas nama selain Allah SWT di mana prosesi penyembelihannya berbeda tempat dari berhala yang dituju, namun memang dimaksudkan untuk persembahan kepada selain Allah SWT ${ }^{23}$. Kedua-duanya tetap sebagai suatu bentuk pengagungan kepada berhala, sehingga haram dimakan, meskipun jenis hewannya pada dasarnya halal.

\section{Kesimpulan dan Saran}

Makanan masyarakat Melayu sudah memenuhi unsur halal dan thoyyib sebagaimana ketentuan fiqih kuliner dalam syariat Islam. Motif masyarakat Melayu hanya memakan makanan dengan kriteria halal dan thoyyib lebih dikarenakan kebiasaan dan tradisi yang diajarkan turun temurun melalui pendekatan petuah dan ajaran para tetua.

Mengutamakan makanan halal dan menghindari makanan haram adalah perkara yang sangat penting dalam kehidupan seorang Muslim. Jika seorang anak manusia terjebak memakan yang haram, maka akan menghalangi terkabulnya doa, setan juga akan menjadikan manusia tersebut mudah dikelabui untuk melakukan kemaksiatan lainnya. Makanan yang haram juga memicu penyakit yang serius. Akibat paling fatal memakan yang haram adalah ancaman menjadi bahan bakar api neraka.

Meskipun masyarakat Melayu sudah pernah mendapat pengajaran tentang konsep makanan halal dan thoyyib, namun pengajaran tersebut belum memuat isi yang sistematik dan belum sampai pada tingkat pemahaman yang menyeluruh. Masyarakat Melayu masih belum memahami secara keseluruhan mengenai konsep makanan madharat.

Jenis makanan yang dihalalkan itu lebih banyak dari pada makanan yang diharamkan, sehingga upaya mengidentifikasi makanan halal sebenarnya sangat mudah yakni dengan memahami criteria makanan haram. Makanan apa saja yang tidak termasuk dalam kriteria makanan haram, maka dengan sendirinya dapat dikategorikan sebagai makanan halal.

Lebih lanjut agar masyarakat Melayu perlu mendapat didikan dan pengajaran dengan muatan yang sistematis dan dilaksanakan secara berkesinambungan demi memperkuat pemahaman masyarakat Melayu terhadap konsep makanan halal dan thoyyib dalam Islam. Muatan lengkap didikan dan pengajaran tersebut hendaknya disampaikan sebagai mata pelajaran muatan lokal yang diajarkan mulai dari sekolah dasar hingga sekolah menengah atau bahkan hingga kurikulum matakuliah pada perguruan tinggi khususnya yang ada di Provinsi Riau.

\footnotetext{
${ }^{22}$ Sarwat, "Seri Fiqih Kehidupan (9) Kuliner."

${ }^{23}$ Qaradhawy and Hafiz, Halal Dan Haram Dalam Islam.
} 


\section{E. Daftar Pustaka}

Ali, Muchtar. "Konsep Makanan Halal Dalam Tinjauan Syariah Dan Tanggung Jawab Produk Atas Produsen Industri Halal." AHKAM: Jurnal Ilmu Syariah 16, no. 2 (2016): 291-306. https://doi.org/10.15408/ajis.v16i2.4459.

Ambali, Abdul Raufu, and Ahmad Naqiyuddin Bakar. "People's Awareness on Halal Foods and Products: Potential Issues for Policy-Makers." Procedia - Social and Behavioral Sciences 121, no. September 2012 (2014): 3-25. https://doi.org/10.1016/j.sbspro.2014.01.1104.

Anggito, Albi, and Johan Setiawan. "Metode Artikel Kualitatif." Jakarta: CV Jejak, 2018.

Hamka, Prof. Tafsir Al Azhar Jilid 1. Jakarta: Gema Insani, 2015.

Khoerunnisa, Tiara, Sunaryo, and Astrid Puspaningrum. "Pengaruh Kepercayaan Agama, Logo Halal, Pemaparan, Dan Alasan Kesehatan Terhadap Kesadaran Merek Dan Keputusan Pembelian Makanan Halal Pada Penduduk Kota Malang.” Ekonomi Bisnis 21, no. 1 (2016): 3645.

Navari, Tim. 1001 Makanan Sehat. Jakarta: Elex Media Komputindo, 2015.

Nugroho, Luky. Tidak Ada Label Halal MUI : Haram? Jakarta: Rumah Fiqih Publishing, 2018.

Pramintasari, T., and I. Fatmawati. "Pengaruh Keyakinan Religius, Peran Sertifikasi Halal, Paparan Informasi, Dan Alasan Kesehatan Terhadap Kesadaran Masyarakat Pada Produk Makanan Halal." Jurnal Manajemen Bisnis 8, no. 1 (2017): 1-33.

Qaradhawy, Yusuf, and Mohd Hafiz. Halal Dan Haram Dalam Islam. Selangor: PTS Publishing House, 2016.

Roza, Ellya. "Internalisasi Nilai Islam Dan Tamadun Melayu Terhadap Perilaku Sosial Orang Melayu Riau.” TOLERANSI: Media Ilmiah Komunikasi Umat Beragama 6, no. 1 (2014): 1635. https://doi.org/10.24014/trs.v6i1.894.

Sabiq, Sayyid. "Fiqhu Sunnah.” Depok: Fathan Media Prima, 2015.

Sarwat, Ahmad. "Seri Fiqih Kehidupan (9) Kuliner.” Jakarta: Rumah Fiqih Publishing, 2017.

Setianto, Adi. "Analisis Ekonomi Masyarakat Melayu Di Dusun Madang Kecamatan Pangkalan Lesung Kabupaten Pelalawan.” Jurnal Mahasiswa Pertanian Universitas Riau, 2015.

Soon, Jan Mei, Mahmood Chandia, and Joe Mac Regenstein. "Halal Integrity in the Food Supply Chain.” British Food Journal 119, no. 1 (2017): 39-51. https://doi.org/10.1108/BFJ-04-20160150 .

Zam, Azyyati Mat, Zulkifflee Mohamed, and Mohd Yaziz Mohd Isa. "A Case Study on Food Caterer : The Halal Food Eco-System ." JAABR, no. May (2014). 